Journal of Applied Pharmaceutical Science Vol. 5 (08), pp. 167-172, August, 2015

Available online at http://www.japsonline.com

DOI: $10.7324 / \mathrm{JAPS} .2015 .50826$

ISSN 2231-3354 (cc) BY-NC-SA

\title{
Phoenix dactylifera Linn as a potential novel anti-oxidant in treating major opioid toxicity
}

\author{
Ibrahim Haruna Sani, Nor Hidayah Abu Bakar, Mohd Adzim Khalili Rohin, Ibrahim Suleiman, Maryam Ibrahim Umar, \\ Nasir Mohamad \\ Opiate Research Interest Group, Faculty of Medicine, Universiti Sultan Zainal Abidin, Medical Campus, Jalan Sultan Mahmud, 20400, Kuala Terengganu, \\ Terengganu. Malaysia.
}

\section{ARTICLE INFO \\ Article history: \\ Received on: 16/02/2015 \\ Revised on: 03/04/2015 \\ Accepted on: 17/06/2015 \\ Available online: 28/08/2015}

Key words:

Phoenix dactylifera L,

Opioids, Neuro protective,

Hepato protective and

Nephro protective.

\begin{abstract}
The use of opioids has gain popularity in the field of medicine especially in treating chronic terminally ill patients. Unfortunately, several adverse effects in relation to its use have been reported. Literature search on the adversity of opioids in treating pain, its paradoxical hyperalgesic effects and susceptibility to addiction were conducted using Pubmed, Embase and Google Scholar without species limitation. This brief article focuses on the corresponding neuro-protective, hepato-protective, anti-inflammatory, ulcero-protective and nephronprotective functions of (Phoenix dactylifera L) to elaborate on evidences, mechanisms, modulatory and pharmacological significance to counteract adverse effects of opioid treatment and provide insight on the underlying mechanisms of addiction.
\end{abstract}

\section{INTRODUCTION}

Phoenix dactyliferaL is one of the species of date palm that grow abundantly in countries around the Arabian Gulf. It belongs to family Arecaceae. The plant is considered as one of the oldest cultivated fruit trees in the Middle East since $6000 \mathrm{BC}$. Due to its abundance and historical tradomedical applications, it has been described as "tree of life" among the Arabian nations. $P$. dactyliferaL is identified by several names in different areas of the globe; the Arabs term it as 'nakhla', the Brazilians call it 'tamareira', while the Chinese and Japanese refer to it as 'wu low zi' and 'natsumeyashi' respectively (Quattrocchi, 1999). Medicinal plants continue to provide valuable therapeutic agents, both in modern and in traditional medicine (Krentz and Bailey, 2005). The role of natural products in curing health problems is gaining acceptance at the global level. There has been a great interest in medicinal uses of $P$. dactylifera as evidenced by the huge research works conducted in the last few decades

\footnotetext{
* Corresponding Author Nor Hidayah Abu Bakar, Opiate Research Interest Group, Faculty of Medicine, Universiti Sultan Zainal Abidin, Medical Campus, Jalan Sultan Mahmud, 20400, Kuala Terengganu, Terengganu. Malaysia. Email: norhidayahabubakar@yahoo.com
}

(Vyawahare et al., 2008). Various parts of date palm are widely used as remedies for numerous disorders, they include memory disturbances, fever, inflammation, paralysis, loss of consciousness, nervous disorders, etc. (Abdelrahman et al., 2012). Phoenix dactylifera $\mathrm{L}$. contains $44-88 \%$ carbohydrates, $6.4-11.5 \%$ dietary fibre, $2.3-5.6 \%$ protein, $0.2-0.5 \%$ fat, 15 different mineral salts and vitamins. Details essentiality of dietary contents found in dates led to its consideration as an ideal food and a balanced diet (Al-Shahib and Marshall, 2003). Date fruit is a good source of energy and rich in nutrients that constitute a significant part of a balanced diet to meet the body need (Ossi et al., 2008; Sadiq et al., 2013). Most of the carbohydrates in dates exist in the form of fructose and glucose, which are easily absorbed by the human body (Ahmed $e t$ al., 1995; Myhara et al., 1999). The dietary fiber content of dates enhances their suitability as ingredients for preparation of fiberbased foods and dietary supplements. Dietary fibers have important therapeutic application and protective effect against conditions such as hypertension, coronary heart disease, obesity, hyperlipidemia and diabetes. It also possesses anticancer, antioxidant, hepato-protective, anti-ulcerative, anti-inflammatory, anti-proliferative, anti-mutagenic, antibacterial, antifungal and antiviral potentials (Tariq et al., 2000; Mallhi et al., 2014). 
An opioid is defined as any psychoactive chemical that is characterized by morphine or other opiates in its pharmacological effects. The opioid drugs have the potential to produce profound analgesia, mood change, physical dependence, tolerance and a rewarding effect which may lead to compulsive drug use. It exerts its effect by binding to opioid-specific receptors, which are principally localized in central and peripheral nervous systems, as well as in the gastrointestinal tract (Reisine and Bell, 1993). The receptors in those organ systems mediate both the beneficial effects and the side effects of the drugs. Opium and its derivatives have been used for centuries, both in a medicinal and leisure manner. Indeed, findings of opium poppy seeds dating as far back as 30,000 years ago suggest the use of opium by Neanderthal man (McDonald and Lambert, 2005), the birth of opioid pharmacology can be traced in 1799, when Friedrich Serturner discovered morphine as the major active ingredient of opium. Morphine and its derivatives are not only used today for the treatment of acute and chronic pain, but also participate in modulation of gastrointestinal, endocrine and autonomic function, as well as a possible role in altered cognitive function (McDonald and Lambert, 2005).

The molecular basis for the acute action of opioids is established via interaction with its specific receptors, of the three pharmacologically distinct opiod receptor types i.e. mu, delta and kappa. Of these receptors, $\mu$-receptor is the main receptor responsible for the action of morphine and some other abused drugs (DeLander et al., 1984). The result of cloning the three different types opioid receptors revealed the interaction of their molecular structures and mechanisms through which mu and other opioid receptors exert their cellular effects through inhibition of adenylyl cyclase activity, closing of voltage-sensitive calcium channel (VSCC) and stimulation of potassium efflux by opening the voltage-gated potassium channels causing hyperpolarization (McDonald and Lambert, 2005; Reisine and Bell, 1993). However opioids have been shown to have predominant inhibitory effects on calcium entry through voltage-gated calcium channels in various cell lines and tissue preparations (Toselli et al., 1997). All these inhibitory actions underlie the decrease in neurotransmitter release and reduction of cellular excitability produced by opioid through Gi or Go subunits (Rabbani et al., 2003). Long-term use of these drugs is associated with undesirable adverse effects, such as oxidative damage to brain, liver, kidney and infertility, as well as constipation.

Thus, safe and effective approach is needed for prevention and treatment of these conditions (Skrabalova et al., 2013). Phoenix dactylifera as a potent antioxidant is rich in potassium, phenolics, flavonoids and low calcium level. Additionally, because of its magnesium content, it is expected that date palm may exert antagonistic effect on adversity of opioid drugs. Opioids have been implicated in oxidative damage to brain, liver and kidney, various studies have shown that long term usage of opioids especially morphine is associated with decrease level of antioxidants and antioxidases (Zhou et al., 2000; Abdelzaher et al., 2010; Zhou et al., 2011; Sumathi et al., 2011). Moreover studies have shown that various parts of $P$. dactylifera are widely used in traditional medicine for the treatment of various disorders which include memory disturbances, fever, inflammation, paralysis, loss of consciousness and nervous disorders (Biglari et al., 2008; Abedi et al., 2012).

Studies have shown that date extract enhances antioxidant processes and prevent oxidative stress. A hydromethanolic extract of $P$. dactylifera fruit showed high antioxidant activity, reducing power, free radical scavenging activity, the antioxidant potential was attributed to phytoconstituents (flavonoids, saponins, tannins, steroids) and vitamin C (Naskar et al., 2010). Furthermore, aqueous $P$. dactylifera extract was found to inhibit significantly the lipid peroxidation, protein oxidation and also exhibited a potent superoxide and hydroxyl radical scavenging activity in a dose dependent manner in vitro (Vyawahare et al., 2008). It can be suggested that $P$. dactylifera extracts can exhibit antagonist effects to oxidative stress induced by opioid adversity.

\section{Neuroprotection}

Studies indicated that opioids especially morphine has been implicated in oxidative damage to brain (Zhou et al., 2000; Abdelzaher et al., 2010; Zhou et al., 2011). Nevertheless, the neuro-protective effect of $P$. dactylifera may counteract the destructive activity of the reactive oxygen species (ROS) that could originate from the opioid abuse. According to the previous reports, pharmacologic agents that possess free radical scavenging or antioxidant properties do have the tendency to reduce brain damage that accompanied by brain ischemia and consequently prevents neurological deficits as observed in $P$. dactylifera use (Gemma et al., 2002; Majid et al., 2008; Al-Taher, 2008). The high concentrations of total phenolic content, flavonoids and anthocyanins as well as the presence of significant quantity of selenoproteins in $P$. dactylifera makes it an excellent candidate for antioxidant processes (Baliga et al., 2011; Wan Ismail et al., 2013), most notably, neuro-protective agents exert their function by protecting nerve cells against oxidative injury. Aqueous Date Fruit Extract (ADFE) was proven to be effective in shielding local neuronal circuitry against focal cerebral ischemia, a property that is most closely related to the oxygen free radical scavenging property of the fruit (Majid et al., 2008).

However similar study conducted to investigate the role of date seed extracts (DSE) in protection against cerebral ischemic damage in rats and suggested that DSE protected cortical neuronal damage induced by middle cerebral artery occlusion credited to its antioxidant activity (Kalantaripour et al., 2012). Moreover, various studies did emphasize on the neuro-protective activity of $P$. dactylifera (Pujari et al., 2014; Mallhi et al., 2014). Zangiabadi and colleagues (2011) reported that $P$. dactylifera could prevent diabetic deterioration and improve pathological parameters of diabetic neuropathy in rats as compared with control groups. Another study by Pujari et al. (2014) did verify the neuromodulatory role of aqueous date extract in reversing adverse effect of bilateral carotid artery occlusion. 
With the aim of exploring the possible anticonvulsant effect of $P$. dactylifera, Al-Taher (2008) observed significant delay in seizure onset time and $50 \%$ reduction in mortality rate among pentylenetetrazole (PTZ) induced seizure mouse models following intraperitoneal administration of 3,4-Dimethoxy toluene (DMT), the major constituent of the $P$. dactylifera. In picrotoxin (Pic), nicotine (Nic) and maximal electroshock (MES)-induced seizure models, DMT administration showed complete inhibition of tonic hind-limb extension (THLE) and exhibited complete protection against mortality. Similarly, injection of DMT $(100 \mathrm{mg} / \mathrm{kg})$ to picrotoxin $(12 \mathrm{mg} / \mathrm{kg})$ induced seizure model resulted in delayed onset time of convulsions and reduced death cases. However, DMT exhibited complete protection against nicotine-induced convulsions $(0.8 \mathrm{mg} / \mathrm{kg})$, the findings suggest involvement in GABAnergic or noradrenergic pathways and possible DMT induced increase in GABA level (Al-Taher, 2008).

\section{Nephroprotection}

Kidneys are delighted organs because they maintain the constancy of the extracellular fluid and receive $20-25 \%$ of cardiac output yet make up less than $1 \%$ of total body mass, they are metabolically active, and thus principally susceptible to toxic injury from agents that disrupt metabolism. Most nephrotoxicity causes either acute or chronic tubular injury, although glomerular injury may sometimes result from drugs or chemicals (Gheshlaghi, 2012; Prakash et al., 2003). Drug-abuse nephropathy and infection in substance abuser causes chronic renal failure (CRF) and nephrotic syndrome in long term usage of drugs. Amphetamine by polyvasculitis mechanism induces CRF (Cooksey, 2012; Gheshlaghi, 2012). Morphine, heroin and cocaine are the most commonly abused drugs, and their use is associated with various types of renal toxicity, including a wide range of glomerular, interstitial and vascular diseases leading to acute or chronic renal failure (Singh et al., 2013). However study conducted by Atici et al. (2005) showed that the histopathological and biochemical changes that follow chronic usage of morphine or tramadol in rat's kidneys pointed out that the risk of increased lipid peroxidation, renal damage due to long term use of opioids, especially morphine. However another study showed that feeding rats with Phoenix dactylifera fruit extract could reduce the levels of plasma creatinine and urea concentration and ameliorate gentamicininduced damage to the proximal tubular regions of the rat kidneys (Al-Qarawi et al., 2008). Nevertheless researchers suggested that vitamins, ascorbic acid, mineral selenium, quercetin and melatonin fractions in date fruit may be responsible for nephron protective activity (Abdel-raheem et al., 2009).

\section{Hepatoprotection}

Chronic opioid intoxication has been shown to cause pathologic changes in the liver in nearly $100 \%$ of cases (Poppers, 2001). Morphine is a widely used opioid in recent years, as an effective analgesic drug for the management of severe pain. It is metabolized mainly in the liver with risk of increased lipid peroxidation and liver damage. Several reports pointed out the risk of hepatic damage due to long term usage of morphine via disturbance of oxidant-antioxidant balance (Samarghandian et al., 2014; Atici et al., 2005). Morphine causes serious oxidative stress in mice hepatocytes and hence results in hepatotoxicity. Antioxidants have shown promising protective effects against morphine caused hepatotoxicity as indicated by decreased plasma alanine content and aspartate transaminase activity (Zhang et al., 2004). However, similar facts suggest the hepatotoxicity induced by morphine and heroin are due to the generation of reactive oxidative species that leads to oxidative stress, leading to increased lipid peroxidation in the liver of abusers (Panchenko et al., 1999). Phoenix dactylifera is famous for its use in treating jaundice and in women before and after delivery in traditional medicine practice. Naskar et al. (2010) reported that water-methanolic extract of date fruit possesses potent antioxidant effect and free radical scavenging activity in addition to its hepatoprotective effect. Date syrup can replace honey by $75 \%$ because of their similarity in sugar content. Palm date syrup showed significant hepatoprotective activity in carbon tetrachloride $\left(\mathrm{CCl}_{4}\right)$ induced hepatotoxicity among New Zealand rabbits (Mallhi et al., 2014). Similar Study conducted by Al-Qarawi et al. (2004) described the reduction of $\mathrm{CCl}_{4}$-induced elevation in plasma enzyme and bilirubin concentration and improved morphological and histological liver damage in rats following administration of aqueous extracts of the flesh and pits of Phoenix dactylifera. The antioxidative and hepatoprotective effects of palm syrups during the first and second experimental periods (4 and $20 \mathrm{~h}$ ) were very clear, since results of plasma ALT and AST and TBARS (from liver homogenate) of the control were significantly higher than those obtained from animals treated with syrups (Zakaria et al., 2012). Moreover, similar study by Ahmed et al (2008) indicated that treatment with aqueous extract of date flesh or by ascorbic acid significantly reduced thioacetamide-induced elevation in plasma bilirubin concentration and enzymes and this study suggests that thioacetamide-induced liver damage in rats can be ameliorated by administration of extract of date flesh or ascorbic acid and this signified the potency of antioxidant activity in date fruit.

\section{Fertility and Sexual Function}

Clinical studies have consistently associated medical and recreational opioid use with hypogonadism and hormone imbalance in both genders. Most studies proposed that the majority of chronic opioid usage are associated with hormonal imbalances and interfere with menstruation in women by limiting the production of luteinizing hormone (LH). Opioid-induced endocrinopathy likely causes the strong association of opioid use with osteoporosis and bone fracture which is likely caused their agonist of opioid receptors in the hypothalamus and the pituitary gland (Brennan, 2013; Colameco, 2009). Studies also have shown that opioid treatment results in hypogonadism (Vuong et al., 2010) by disrupting the normal pulsatility of gonadotropin releasing hormone $(\mathrm{GnRH})$ secretion with subsequent reduction of the release of luteinizing hormone (LH) and follicle-stimulating 
hormone (FSH) from the pituitary gland and of testosterone or estradiol (E2) from the gonads (Adams et al., 1993). The Phoenix dactylifera, date palm is used as therapy for male infertility and impotency in traditional medicine. The presence of $\alpha$-amirin, triterpenoidalsaponins, estrone, estradiol, estriol and flavonoids in date palm may explain the facilitatory role of the fruit on sexual function by increasing the release of dopamine (DA) in the nucleus accumbens (Abedi et al., 2014). Oral administration of date fruit suspensions at doses of 120 and $240 \mathrm{mg} / \mathrm{kg}$ improved the sperm count, motility, morphology and DNA quality with an associated increase of the weight of testis and epididymis (Bahmanpour et al., 2006). However similar study conducted by Abediet al (2012) indicated that Phoenix dactylifera pollens can enhance penile erection, influence sexual arousal and improve performance. It seems the primary site of its action may be the testis; however, its possible effect on the hypothalamo-hypophyseal axis may serve as a better candidate. Phoenix dactylifera fruit extract have been shown to increase sperm count in guinea pigs and to enhance spermatogenesis and increase the concentration of testosterone, follicle stimulating hormone (FSH) and luteinizing hormone (LH) in rats (Elgasim et al., 1995).

Study conducted by Abediet al (2014) reveal that male rats treated with aqueous date extract has high sexual behavior when exposed to estrous female counterpart than control. However similar study conducted by Bajpayee (1997) and Bahmanpouret al (2006), indicated that the effect of $P$. dactylifera in reproductive system of adult male rats and is exerted by improving the quality of sperm parameters and consequently improves fertility. $P$. dactylifera pollens were reported to contain estrogenic materials, estrone, which gives the fruit its characteristic of gonadal stimulating potency that improve male infertility and promote gonadotrophin activity in the rat (Bajpayee, 1997).

\section{Gastrointestinal Protection}

Treatment of opioid-induced gut dysfunction: Opioid analgesics are the mainstay in the treatment of moderate-to-severe pain, unfortunately, adverse effects can severely compromise the therapeutic use offered by these drugs, the gastrointestinal tract (GIT) is one of the main targets of their unwanted actions, the most common and devastating being constipation (Holzer, 2004). Constipation develops in many people on opioid because it directly inhibits and disrupts normal functions of the intestinal tract. Since tolerance to this problem does not develop readily, most patients on long-term opioid will need a laxative (McCarberg, 2013). The opioid-induced motor stasis results from blockade of gastrointestinal peristalsis and fluid secretion pathways, and reflects the action of the endogenous opioid system in the gut (Holzer, 2004). P. dactylifera fruit with its high fibers and laxative property has been demonstrated by quantifying their effect on gastrointestinal transit in mice, compared with the control, the animals that received date fruits extracts emptied more of their gastrointestinal content which ranged from 4 to $22 \%$ (AlQarawi et al., 2003). However study conducted by Al-Qarawiet al (2005) indicated that the aqueous and ethanolic extracts of the $P$. dactylifera fruit and pits were effective in ameliorating the severity of gastric ulceration and mitigating the ethanol-induced increase in histamine and gastrin concentrations, and the decrease in mucin gastric levels. The ethanolic extract was more effective than the rest of the other extracts used. It is suggested that the basis for the gastro protective action of date extracts may be multi-factorial, and may include its antioxidant action.

\section{Anti-Inflamatory and Analgesic Function}

Inflammation is a complex phenomenon comprising of a humoral (cytokines) and cellular (leukocytes, monocytes and macrophages) mechanisms. It is usually a self-limiting event. Chronic inflammation continuously produces inducible cyclooxygenase (COX-2) that increases the production of prostaglandin E2 (PGE2) and reduces the E-cadherin protein (Sciarra et al., 2008). It also produces free radicals as several reactive oxygen species (ROS) (Rigas and Sun, 2008). Opioidinduced hyperalgesia has been observed in some patients, whereby individuals using opioids to relieve pain may paradoxically experience more pain as a result of their medication. This phenomenon, although uncommon, as seen in some palliative care patients, most often when dose is escalated rapidly (Vella-Brincat and Macleod, 2007). Additionally, intravenous opioid drug users are at high risk of various infections including hepatitis and human immunodeficiency virus infection. The various parts of Phoenix dactylifera are widely used in traditional medicine for the treatment of various disorders which may include memory disturbances that follows neuro inflammation (e.g postoperative cognitive dysfunction), fever, systemic inflammation and neuropathic pain (Abedi et al., 2012). P. dactylifera possesses significant anti-inflammatory activity and recent report on the Ajwa dates showed that ethyl acetate, methanolic, and water extracts of Ajwa dates inhibit the lipid peroxidation, cyclooxygenase enzymes COX-1 and COX2 activity (Zhang et al., 2013). However a study by Elberry et al. (2011) suggested that anti-inflammatory and antiproliferative activities of $P$. dactylifera pollen may serve a potential protective effect in atypical prostatic hyperplasia (APH) in Wistar rats through modulation of cytokine expression and/or upregulation of their autocrine/paracrine receptors. Shabani et al. (2013) have reported that $P$. dactylifera extract decreases thermal hyperalgesia and can prevent pain resulting from diabetic neuropathy. Mohamed and Al-okbi (2004) suggested the use of the fruits in the treatment of headache and arthritis. Moreover, in a similar context, anti-arthritis activity of Phoenix dactylifera was demonstrated in rats (Doha et al., 2004).

\section{CONCLUSION}

Although increased education on prescription and use of opioids is important in achieving good pain management, adverse effects such as pruritus, postoperative nausea and vomiting (PONV), sedation, hypotension, respiratory depression and opioid induced constipation do need pharmacologically active agents that have the capacity to individually counteract these complications by 
interfering with opioid activity and their receptor activation pathways. Interestingly, phytochemistry and immense pharmacologic properties of Phoenix dactylifera such as its haemopoietic, antioxidant, neuro protective, anti-ulcerative, hepato protective and cerebro protective activities can be exploited to ameliorate adverse effects of opioid use. This may lead to development of novel therapeutic approach to managing side effects of opioid administration.

\section{REFERENCES}

Abdel-raheem IT, Abdel-ghany AA and Mohammad GA. Protective effect of quercetin against gentamycin induced nephrotoxicity in rats. Biolology and pharmaceutical bulletin.2009; 33:6167.

AbdelrahmanHA,Fathalla SI, Mohamed AA, Jun HK and Kim DH. Protective Effect of Dates (Phoenix dactylifera L.) And Licorice (Glycyrrhizaglabra) on Carbon Tetrachloride-Induced Hepatotoxicity in Dogs.Global Veterinaria. 2012; 9 (2): 184-191.

Abdel-Zaher AO, Abdel-Rahman MS, and Elwasei FM. Blockade of Nitric Oxide Overproduction and Oxidative Stress by Nigella sativa Oil Attenuates Morphine-Induced Tolerance and Dependence in Mice. Neurochem Res. 2010; 35:1557-1565.

Abedi A, Karimian S.M, Parviz M, Mohammadi P, and Roudsari HRS.Effect of aqueous extract of Phoenix dactylifera pollen on dopamine system of nucleus accumbens in male rats.Neuroscience and medicine.2014; 5:49-59.

Abedi, A., Parviz, M., Karimian, S.M. and SadeghipourRodsari, H.R.The Effect of Aqueous Extract of PhoenixdactyliferaPollen Grain on Sexual Behavior of Male Rats. Journal of Physiology and Pharmacology Advances.2012; 2: 235-242.

Adams ML, Sewing B, Forman JB, Meyer ER, Cicero TJ.Opioid-induced suppression of rat testicular function.J Pharmacol ExpTher 1993; 266:323-328.

Ahmed IA, Ahmed AWK and Robinson RK.Chemical composition of date varieties as influenced by the stage of ripening. Food Chem. 1995; 54: 305-309.

Ahmed MB, Hasona NA and Selemain HA.Protective Effects of Extract from Dates (Phoenix Dactylifera L.) and Ascorbic Acid on Thioacetamide-Induced Hepatotoxicity in Rats.Iranian Journal of Pharmaceutical Research. 2008; 7 (3): 193-201.

Al-Qarawi AA, Abdel-Rahman H, Mousa HM, Ali BH and ElMougy SA.Nephroprotective action of Phoenix dactylifera.In gentamicininduced nephrotoxicity. Pharm Biol 2008; 4: 227-230.

Al-Qarawi AA, Abdel-Rahman H, Mousa HM, Ali BH and ElMougySA.The ameliorative effect of dates (Phoenix dactylifera L.) on ethanol-induced gastric ulcer in rats. Journal of Ethnopharmacology. 2005; 98: 313-317.

Al-Qarawi AA, Ali BH, Al-Mougy SA and Mousa HM. Gastrointestinal transit in mice treated with various extracts of date (Phoenix dactylifera L.). Food and Chemical Toxicology. 2003; 41(1): $37-$ 39.

Al-Qarawi AA, Mousa HM, Ali BH, Abdel-Rahman H, ElMougy SA(2004). Protective effect of extracts from Dates (Phoenix dactylifera) on carbon tetrachloride-induced hepatotoxicity in rats. Intern J Appl Res Vet Med. 2004; 2: 176-180.

Al-Shahib W and Marshall RJ. The fruit of the date palm: its possible use as the best food for the future. International journal of food sciences and nutrition. 2003; 54(4): 247-259

Al-Taher AY. Anticonvulsant effects of 3, 4-Dimethoxy toluene, the major constituent of Phoenix dactylifera L Spathe in mice. Scientific Journal of King Faisal University (Basic and Applied Sciences). 2008; 9 (2): 115-123.

Atici S, Cinel I, Cinel L, Doruk N, Eskandari G and Oral U. Liver and kidney toxicity in chronic use of opioids: An experimental long term treatment model. J. Biosci. 2005; 30: 245-252.
Bahmanpour S, Talaei T, Vojdani Z, Panjehshahin MR, Poostpasand LA, Zareei S, Ghaeminia M. Effect of Phoenix Dactylifera pollen on sperm parameters and reproductive system of adult male rats.s Iran J Med Sci. 2006; 31(4): 208-212.

Bajpayee, KK. Ethnobotany of phoenix (Archaeae).Journal of Economic and axonomic Botany 1997; 21: 155-7.

Baliga MS, Baliga BRV, Kandathil SM, Bhat HP, Vayalil PK. A review of the chemistry and pharmacology of the date fruits (Phoenix dactylifera L.). Food Research International.2011; 44: 1812-1822.

Biglari F, AlKarkhi AFM, Azhar ME. Antioxidant activity and phenolic content of various date palm (Phoenix dactylifera) fruits from Iran. Food Chemistry. 2008; 107: 1636-1641.

Brennan MJ. "The effect of opioid therapy on endocrine function". Am. J. Med. 2013; 126 (3): 12-8.

Colameco S and Coren JS. (January 2009). "Opioid-induced endocrinopathy". J Am Osteopath Assoc. 2009; 109 (1): 20-5. PMID 19193821.

Cooksey C. Health concerns of heavy metals and metalloids. Sci Prog 2012; 95: 73-88.

DeLander GE, P ortoghese PS, Takemori AE: Role of spinalmu opioid receptors in the development of morphinetolerance and dependence. J Pharmacol Exp Ther. 1984; 231: 91-96.

Doha MA, Sahar YA. In vivo evaluation of antioxidant and anti-inflammatory activity of different extracts of date fruits in adjuvant arthritis. Pol. J. Food Nutr. Sci, 54(4), 2004, 397-402.

Elberry AA, Mufti ST, Al-Maghrabi JA, Abdel-Sattar EA, Ashour OM, Ghareib SA and Mosli HA. Anti-inflammatory and antiproliferative activities of date palm pollen (Phoenix dactylifera) on experimentally-induced atypical prostatic hyperplasia in rats. J Inflamm (Lond).2011; 23: 40.

Elgasim EA, Alyousif YA, Homeida AM: Possible hormonal activity of date pits and fleshfed to meat animals. Food Chem. 1995; 52 $149-150$

Gemma C, Mesches MH, Sepesi B, Choo K, Holmes DB, Bickford PC. Diets enriched in foods with high antioxidant activity reverse age-induced decrease in cerebellar-adrenergic function and increases in proinflammatory cytokines. J Neurosci 2002; 22(14):6114-120.

Gheshlaghi F. Toxic renal injury at a glance. J Renal Inj Prev. 2012; 1(1): 15-16

Holzer P. Opioids and opioid receptors in the enteric nervous system: from a problem in opioid analgesia to a possible new prokinetic therapy in humans.Neurosci. Lett. (2004) 361:192-195.

Kalantaripour TP, Shekaari MS, Basiri M and Najar AG.Cerebroprotective effect of date seed extract (Phoenix dactylifera) on focal cerebral ischemia in male rats. J. Biol. Sci. 2012; 1-6.

Krentz AJ, Bailey CJ. Oral antidiabetic agents: current role in type 2 diabetes mellitus. Drugs 2005; 65: 385 - 411.

Majid AS, Marzieh P, Shahriar D, Zahed SK, Pari KT. Neuroprotective effects of Aqueous Date Fruit Extract on focal cerebral ischemia in rats. Pak J Med Sci 2008; 24(5):661-65.

Mallhi TH, Qadir MI, Ali M, Ahmad B, Khan YH and Rehman AU.Ajwa Date (Phoenix dactylifera): An Emerging Plant in Pharmacological Research. Pak. J. Pharm. Sci. 2014; 27(3): 607-616.

McCarberg BH. "Overview and Treatment of Opioid-Induced Constipation".Postgraduate Medicine. 2013; 125(4): 7-17.

McDonald J. And Lambert D. Opioid receptors. Continuing Education in Anaesthesia, Critical care and Pain 2005; 5(1): 22-25.

Mohamed DA and Al-okbi SY.In vivo evaluation of antioxidant and anti-inflammatory activity of different extract of date fruit in adjuvant arthritis.J food Nutr Sci. 2004; 13: 397-402.

Myhara, R. M., Karkalas, J. and Taylor, M. S. 1999. The composition of maturing Omani dates. J. Sci. Food Agric. 1999; 79: 1345 1350 .

Naskar S. Islam A.Mazumder UK.Saha P. Haldar PK and Gupta M.In Vitro and In Vivo Antioxidant Potential of Hydromethanolic Extract of Phoenix dactylifera Fruits. J Sci. Res. 2010; 2 (1): 144-157.

Ossi, C.D and Ndukwe, C.M., The nutritional evaluation of cola lepidota, Book of proceeding International Conference, Chemical society of Nigeria, 2008; 5(2): 150-154. 
PanchenkoLF,Pirozhkov SV, Nadezhdin AV, Baronets VI andUsmanova NN. Lipid peroxidation peroxyl radical-scavenging system of plasma and liver and heart pathology in adolescence heroin users.Vopr. Med. Khim. 1999; 45, 501-564.

Poppers PJ. Hepatic drug metabolism and anesthesia. Anaesthesist 1980; 29: 55-58.

Prakash J, Sen D, Kumar NS, Kumar H, Tripathi LK, Saxena RK. Acute renal failure due to intrinsic renal diseases: review of 1122 cases. Ren Fail 2003; 25: 225-33.

Pujari RR, Vyawahare NS, and Thakurdesai PA. Neuroprotective and antioxidant role of phoenix dactylifera in permanent bilateral common carotid occlution in rats. Journal of Acute Disease. 2014: 104-114.

Quattrocchi, U. CRC World Dictionary of Plant Nmaes: Common Names, Scientific Names, Eponyms, Synonyms, and Etymology. 1999; 3: CRC Press.

Rabbani M, Jafarian A and Sobhanian MH. Comparison of acute and chronic effects of nifedipine on naloxone precipitated morphine withdrawal in mice. J. Islamic Rep. Iran. 2003; 17 (3): 251-257.

Reisine $\mathrm{T}$ and Bell GI.Molecular biology of opioid receptors. Trends Neurosci 1993; 16:506-10.

Rigas B and Sun Y: Induction of oxidative stress as a mechanism of action of chemopreventive agents against cancer. $\mathrm{Br} \mathbf{J}$ Cancer 2008, 98:1157-1160.

SadiqIS,Izuagie T, Shuaibu M, Dogoyaro AI, Garba A and Abubakar S. The Nutritional Evaluation and Medicinal Value of Date Palm (Phoenix dactylifera). Int. J. Modern Chem. 2013; 4(3): 147-154.

Samarghandian S, Afshari R and Farkhonden T. Effect of longterm treatment of morphine on enzymes oxidative stress indices and antioxidant status in male rats' liver. Int J ClinExp Med 2013; 7(4): 1449 1453.

Sciarra A, Mariotti G, Salciccia S, Gomez AA, Monti S, Toscano V, DiSilverio F: Prostate growth and inflammation. J Steroid BiochemMol Biol. 2008; 108:254-260.

Shabani M, Zangiabadi N and Asadi-Shekaari M. Evidence for Positive Effects of Date Extract That Attenuates Thermal Hyperalgesia in a Diabetic Rat Model of Neuropathic Pain. Neuroscience \& Medicine. 2013; 4: 16-22.

Singh VP, Singh N, andJaggi AS. A Review on Renal Toxicity Profile of Common Abusive Drugs.Korean J PhysiolPharmacol. 2013; 17: $347-357$.

Skrabalova J, Drastichova Z and Novotny J. Morphine as a Potential Oxidative Stress-Causing Agent. Mini-Reviews in Organic Chemistry.2013; 10: 367-372.

Sumathi T, Nathiya VC, and Sakthikumar M. Protective effect of bacoside-A against morphine-induced oxidative stress in rats.Indian $\mathrm{J}$ Pharm Sci. 2011; 73: 409-15.

Tariq N, Jenkins DJA, Vidgen E, Fleshner N, Kendall CWC, Story JA, Singer W, D'Coosta M. and Struthers N. Effect of soluble and insoluble fiber diets on serum prostate specific antigen in men. J. Urol. $2000 ; 163.114-118$.
Toselli M, Tosetti P, TagliettiV: Mu and delta opioid receptor activation inhibits omega-conotoxin-sensitive calcium channels in a voltage- and time-dependent mode in the human neuroblastoma cell line SH-SY5y' Pflugers Arch. 1997; 433: 587-596.

Vella-Brincat $\mathrm{J}$ and Macleod AD. "Adverse effects of opioids on the central nervous systems of palliative care patients". J Pain Palliat Care Pharmacother. 2007; 21 (1): 15-25. doi:10.1080/J354v21n01_05. PMID 17430825

Vuong C, Van Uum SH, O’Dell LE, Lutfy K, Friedman TC.The effects of opioids and opioid analogs on animal and human endocrine systems.Endocr Rev 2010; 31:98-132.

Vyawahare N, Pujari R, Khsirsagar A, Ingawale D, Patil M and Kagathara V. Phoenix dactylifera: An update of its indegenoususes, phytochemistry and pharmacology. The Int. Journal of Pharmacol. 2008; 7(1): 1-14.

Wan Ismail WI, MohdRadzi MNF. Evaluation on the Benefits of Date Palm (Phoenix dactylifera) to the Brain. AlternInteg Med. 2013; 2: 115. doi:10.4172/2327-5162.1000115

Zakaria, A.-S., Mohamed, A.-M., et al. In vivo antioxidative and hepatoprotective effects of palm date fruits (Phoneixdactylifera). International Journal of Pharmacology, 2012; 8(3), 185-191.

Zangiabadi, N., Asadi-Shekaari, M., Sheibani, V., Jafari, M., Shabani, M., Asadi, A. R., et al. Date Fruit Extract Is a Neuroprotective Agent in Diabetic Peripheral Neuropathy in Streptozotocin-Induced Diabetic Rats: A Multimodal Analysis. Oxidative Medicine and Cellular Longevity, 2011: 1-9.

Zhang CR, Aldosari SA, Vidyasagar PS, Nair KM and Nair MG. Antioxidant and anti-inflammatory assays confirm bioactive compounds in Ajwa Date fruit. J Agric Food Chem, 2013; 61: 5834-5840.

Zhou J, Li Y, Yan G, Bu Q, Lv L, Yang Y, Zhao J, Shao X, Deng Y, Zhu R, Zhao Y, and Cen X. Protective role of taurine against morphine-induced neurotoxicity in C6 cells via inhibition of oxidative stress. Neurotox.Res. 2011; 20: 334-342.

Zhou JF, Yan XF, Ruan ZR, Peng FY, Cai D, Yuan H, et al. Heroin abuse and nitric oxide, oxidation, peroxidation, lipid peroxidation. Biomed Environ Sci 2000; 13:131-9.

\section{How to cite this article:}

Ibrahim Haruna Sani, Nor Hidayah Abu Bakar, Mohd Adzim Khalili Rohin, Ibrahim Suleiman, Maryam Ibrahim Umar, Nasir Mohamad. Phoenix dactylifera linn as a potential novel antioxidant in treating major opioid toxicity. J App Pharm Sci, 2015; 5 (08): 167-172 